\title{
TEMPERATURE-DEPENDENT ELECTRICAL CHARACTERISTICS OF DISC-SHAPED COMPACTS FABRICATED USING CALCINED EGGSHELL NANO POWDER AND DRY CASSAVA STARCH
}

\author{
Ubong W. Robert, Sunday E. Etuk, Okechukwu E. Agbasi, Ubong A. Iboh, Sunday S. \\ Ekpo
}

\begin{abstract}
Disc-shaped compacts were fabricated from two mix proportions of calcined eggshell nanopowder and dry cassava starch and then used as test samples. The electrical resistance $(R)$, thermal sensitivity index $(\beta)$ and electronic activation energy $\left(E_{a}\right)$ of the samples measured over a temperature range from 35 to $75^{\circ} \mathrm{C}$ were found to decrease non-linearly in values with increasing temperature. It was also observed that the results obtained ( $R=3.691 E 6 \Omega-6.210 E 7 \Omega, \beta=3812 \mathrm{~K}-5316 \mathrm{~K}$ and $E a=0.33 \mathrm{eV}-0.46 \mathrm{eV}$ ) fulfill market requirements by comparing very well with the established values for NTC thermistors. Hence, from manufacturing viewpoint, recycling of chicken eggshell wastes and cassava effluents can avail electronic industry with promising and alternative materials for fabrication of temperature sensing / monitoring / control devices suitable for engineering applications. This will also help to reduce environmental pollution.
\end{abstract}

Keywords: Calcium Oxide, Carr's Compressibility Index, Eggshell, Poultry, Recycling, Steinhart-Hart Coefficients

\section{INTRODUCTION}

Through adoption of technological innovations in agriculture, commercial poultry farming has become a fast yielding business in recent times. For instance, the practice of animal breeding facilitates the possibility of producing commercial chickens (known as layers) that can lay several eggs within few days unlike how local (indigenous) breed can do [1]. This, no doubt, has contributed a great deal to the large volume of eggs production observed worldwide. In Africa, Nigeria was reported to be the largest producer of eggs with annual production capacity of 10.3 billion eggs. This is evident in Vanguard newspaper publication dated November 23, 2016 on how to sustain poultry industry in an economic recession. Also, on the basis of total weight (in kilograms) of eggs before processing, reports given by [2] on global eggs production showed that China is the largest producer ( 24.8 billion) followed by USA ( 5.6 billion) and then India (3.8 billion). It is noteworthy that the trend observed in the aforementioned reports is in agreement with the United Nation's Food and Agriculture Organization that by 2015, egg production will have reached 70.4 metric tons.

\footnotetext{
Ubong W. Robert, Ubong A. Iboh: Department of Physics, Akwa Ibom State University, Ikot Akpaden, Mkpat Enin, Nigeria

Sunday E. Etuk, Sunday S. Ekpo: Department of Physics, University of Uyo, Uyo, Nigeria

Okechukwu E. Agbasi: Department of Physics, Michael Okpara University of Agriculture, Umudike, Nigeria
} 
Chicken eggs are known to be a great source of cheap protein that is important especially to children, the elderly and pregnant women in areas of solving malnutrition problem [3], thereby playing a significant role in fulfilling annual nutrition demand. By considering the fact that commercial poultry farming can help to diversify a nation's economy, create great employment opportunities for job seeking people and make people millionaires [4 - 5], agriculture may be regarded as the future of a country. Several areas in which multiple uses of processed chicken eggs can be found include (but are not limited to) biotechnology/tissue culture, as well as chemical (cosmetics), food, art (painting and photography) and pharmaceutical industries [6].

Processing of chicken eggs usually generates some waste materials. Observably, chicken eggshell is the major waste from such activity. According to Hunton [7], chicken eggshell is $95-97 \%$ calcium carbonate $\left(\mathrm{CaCO}_{3}\right)$ crystals which are stabilized by a protein matrix. In his work, Hecht [8] noted that 150,000 tons of eggshell waste was generated annually by the United States food industry alone. Though [9] opined that $26.3 \%$ of eggshell wastes is discarded in municipal dumps, it has been observed that since eggshells and the attached membrane attract vermin, many landfills are not willing to take the wastes [10]. Equally worrisome is the fact that disposal of wastes by burning can cause a serious environmental pollution with the potential of posing risk to human health. Therefore, it is obviously necessary to explore a convenient way of disposing such wastes in order to significantly reduce the adverse effect they might cause to humans and/or environment. As such, this work is designed to recycle eggshell waste and then investigate the electrical behavior of the new material developed so as to determine its suitability for engineering applications, especially in situations where temperature variation is inevitable.

\section{THEORY}

Temperature has a great deal of influence on the behavior of materials. In a solid material, all the atoms are in continuous state of motion which consists of vibrations around a point in the structure. As the material's temperature increases, a greater amount of thermal energy is converted into mechanical energy and that causes such vibrations to increase as well. Mgbenu et al [11] averred that temperature is directly related to the average kinetic energy of the atoms composting a material.

Since the number of collisions between electrons in atoms is affected by the vibrations of the atoms, it follows that electrical resistance of a material is affected by temperature. Now, if temperature effect is neglected for a time being, the electrical resistance of a material can be expressed as [12]:

$$
\mathrm{R}=\frac{\mathrm{pl}}{\mathrm{A}}
$$

where $\mathrm{R}=$ electrical resistance, $\rho=$ electrical resistivity, $1=$ length (distance between cross-sectional surfaces) of the material and $\mathrm{A}=$ cross sectional area of the material.

Without neglecting temperature effect, the variation caused by it on electrical parameters differs among different classes of materials used. In ceramics, increase in temperature may bring about increase or decrease in the value of their electrical parameters. Based on the latter situation, the effect of temperature on resistivity values and thermal or material constant (thermal sensitivity index) for a device made of ceramic materials can be represented by the following well-known Arrhenius relation [13]: 


$$
\rho=\rho_{0} \exp \left[\frac{E_{a}}{k T}\right]
$$

with

$$
\beta=\frac{E_{\mathrm{a}}}{\mathrm{k}}
$$

where $\rho=$ electrical resistivity at a given temperature, $\rho_{0}=$ electrical resistivity at infinite temperature, $\mathrm{T}=$ absolute value of the given temperature, $\mathrm{E}_{\mathrm{a}}=$ electronic activation energy, $\mathrm{k}=$ Boltzmann's constant and $\beta=$ thermal sensitivity index.

In this case, applying Eqns. (1), (2) and (3) yields a simple exponential approximation for resistance-temperature relationship as:

$$
\mathrm{R}=\mathrm{R}_{0} \exp \left(\frac{\beta}{\mathrm{T}}\right)
$$

where $R_{o}$ is the electrical resistance at infinity and is approximately independent on temperature.

Thus, for a narrow temperature range, the beta parameter ( $\beta$-value) can be estimated for the device as:

$$
\beta=T_{2}\left(\frac{T_{1}}{T_{2}-T_{1}}\right) \ln \left(\frac{R_{1}}{R_{2}}\right)
$$

where $R_{1}$ and $R_{2}$ are the electrical resistance values measured at temperature $T_{1}$ and $\mathrm{T}_{2}$ respectively.

With this, the device's temperature coefficient of resistance, $\alpha$ (i.e. the change in its resistance for a unit change in temperature) can be expressed mathematically, thus

$$
\begin{aligned}
& \alpha= \pm\left[\frac{1}{R_{1}}\left(\frac{R_{2}-R_{1}}{T_{2}-T_{1}}\right)\right] 100 \% \\
& \alpha= \pm\left(\frac{\beta}{T^{2}}\right) 100 \%
\end{aligned}
$$

and the negative sign is considered only if the resistance values vary inversely with temperature.

However, when considering wider temperature ranges of the device Steinhart-Hart equation becomes a suitable model that gives an accurate description of the resistancetemperature relationship. In its simplified form, the equation yields the following thirdorder approximation which provides the best resistance-temperature transfer function for faithful characterization of the device's performance [14]:

$$
\frac{1}{\mathrm{~T}}=\mathrm{a}+\mathrm{b} \ln \mathrm{R}+\mathrm{C}(\ln \mathrm{R})^{\mathrm{a}}
$$

where $a, b$ and $c$ are the Steinhart-Hart coefficients obtained at high, middle and low operating points for the device within the temperature range of interest.

Such parameters relate with $\beta$ and $\alpha$ thus:

$$
\beta=\sqrt{\left(\frac{b}{3 c}\right)^{3}+\left(\frac{c}{2}\right)^{2}}
$$

and 


$$
\alpha=\frac{1}{c}\left[a-\left(\frac{1}{T}\right)\right]
$$

\section{EXPERIMENTAL}

\section{Preparation of Starting Materials}

Dry cassava starch and calcined eggshell nanopowder were used as starting materials. The cassava starch was prepared as described elsewhere [15]. Also, the calcined eggshell nanopowder was prepared from fresh chicken eggshells collected as waste materials from University cafeteria in Akwa Ibom State, Nigeria, as follows:

The eggshells were thoroughly washed with distilled water several times to remove all unwanted materials from them and the clean shells obtained were allowed to dry under ambient conditions. This was followed by crushing of the dry eggshells into powdery form by means of agate mortar and pestle. The crushed material was screened and the quantity of it that passed through 140-mesh screen was calcined in a Muffle ASCO furnace at $1000^{\circ} \mathrm{C}$ for 5 hours. This was necessary in order to obtain Calcium Oxide $(\mathrm{CaO})$ with purity of about $99.2 \%$ from the eggshells. On cooling to $35^{\circ} \mathrm{C}$, the calcined eggshell powder was ball-milled using Emax high energy ball miller (manufactured by RETSCH, GmbH) at $500 \mathrm{~min}^{-1}$ for 8 hours. This machine is capable of reducing particle sizes of material feed from about $5 \mathrm{~mm}$ to as fine as less than $80 \mathrm{~nm}$. Based on the procedure outlined in [16], Carr's compressibility index of the as-prepared calcined eggshell nanopowder and that of the dry cassava starch were determined. Such determinations were made five times and the mean value was calculated with standard error in each case.

\section{Samples Fabrication and Testing}

Two mix proportions of the starting materials were used (Tab. 1) and in each case, the materials were mixed and blended using the ball miller. After wetting of the mixture with distilled water (in 1:3 ratio by weight of the dry cassava starch to distilled water), it was put in a copper vessel and heated using a hot plate until the wet mixture became gummy. Then after, five disc-shaped compacts of diameter $1.15 \pm 0.01 \mathrm{~cm}$ and thickness $0.25 \pm 0.01 \mathrm{~cm}$ were made by uniaxially pressing each of them at $700 \mathrm{MPa}$ for 240 seconds. The pressed disc was sintered in air at $1000^{\circ} \mathrm{C}$ for 1 hour 30 minutes after which silver paste was applied on their opposite faces before they were subjected to heat treatment for metallization at $850{ }^{\circ} \mathrm{C}$ for 15 minutes. Silver wires were then attached as electrode leads for the fabricated samples.

Measurement of electrical resistance of each of the samples was done by means of LCR meter (Model 9183 Lutron) for temperature range of 35 to $75^{\circ} \mathrm{C}$. The mean resistance values and other electrical parameters were determined. Also, Steinhart-Hart coefficients were determined and then used to obtain simulated electrical resistance values of the samples at corresponding temperatures.

\section{RESULTS AND DISCUSSION}

Carr's compressibility indices of CEN and DCS are presented in Table1 and the results of the experimental investigation are presented in Tab. 2. In any fabrication / manufacturing process, the flow of powdery solids is very important since flowability is inversely proportional to compressibility (being an expression of the ability of such solids to reduce their volume when subjected to normal stress). Now, by considering that a Carr's index of less than $15 \%$ signifies high flowability $[17,18]$, it can be adjudged that the mean Carr's compressibility index values of $11.41 \pm 0.01 \%$ and $11.20 \pm 0.01 \%$ obtained for the 
CEN and DCS, respectively imply the existence of very good content uniformity of the starting materials in the samples as fabricated and used.

Tab. 1. Particulars of the starting materials used

\begin{tabular}{|l|l|l|l|l|l|l|l|}
\hline \multirow{2}{*}{$\begin{array}{l}\text { Material } \\
\text { code }\end{array}$} & \multicolumn{6}{|l|}{ Carr's Compressibility Index, CI (\%) } & $\begin{array}{l}\text { Mix proportion } \\
\text { of CEN:DCS by } \\
\text { weight }\end{array}$ \\
\cline { 2 - 8 } & 1 & 2 & 3 & 4 & 5 & Mean \pm Std. error & \\
\hline CEN & 8.63 & 8.65 & 8.62 & 8.62 & 8.63 & $8.63 \pm 0.01$ & $6: 1$ \\
\hline DCS & 11.21 & 11.19 & 11.22 & 11.22 & 11.18 & $11.20 \pm 0.01$ & $9: 1$ \\
\hline
\end{tabular}

CEN = Calcined Eggshell Nanopowder, DCS = Dry Cassava Starch

From Tab. 2, it can be seen that even with the adjustment made in the proportion of the CEN, the electrical resistance of the samples still varies inversely with temperature over the range considered. Also, increase in the proportion of the CEN is observed to bring about decrease in the resistance of the samples at corresponding temperatures. While this suggests that the CEN is of lower electrical resistance compared to the DCS, it could be occasioned by calcium (a metallic element) being present as a critical component of the CEN.

Tab. 2. Summary of the experimental results

\begin{tabular}{|c|c|c|c|c|c|c|}
\hline \multirow{3}{*}{$\mathrm{T}\left({ }^{0} \mathrm{C}\right)$} & \multicolumn{6}{|c|}{ Values of samples parameters per mix proportion of CEN: DCS } \\
\hline & \multicolumn{3}{|c|}{$6: 1$} & \multicolumn{3}{|c|}{ 9: 1} \\
\hline & $\mathrm{R}(\Omega)$ & $\beta(\mathrm{K})$ & $\mathrm{E}_{\mathrm{a}}(\mathrm{eV})$ & $\mathrm{R}(\Omega)$ & $\beta(\mathrm{K})$ & $\mathrm{E}_{\mathrm{a}}(\mathrm{eV})$ \\
\hline 35.0 & $6.210 \mathrm{E} 7$ & 5316 & 0.46 & $4.320 \mathrm{E} 7$ & 5102 & 0.44 \\
\hline 40.0 & $5.076 \mathrm{E} 7$ & 5148 & 0.44 & $3.364 \mathrm{E} 7$ & 4922 & 0.42 \\
\hline 45.0 & $3.760 \mathrm{E} 7$ & 4986 & 0.43 & $2.324 \mathrm{E} 7$ & 4748 & 0.41 \\
\hline 50.0 & 2.714 E7 & 4830 & 0.42 & $17.078 \mathrm{E} 6$ & 4579 & 0.39 \\
\hline 55.0 & $2.065 \mathrm{E} 7$ & 4678 & 0.40 & $12.559 \mathrm{E} 6$ & 4416 & 0.38 \\
\hline 60.0 & $15.752 \mathrm{E} 6$ & 4531 & 0.39 & $9.242 \mathrm{E} 6$ & 4258 & 0.37 \\
\hline 65.0 & $12.031 \mathrm{E} 6$ & 4388 & 0.38 & $6.804 \mathrm{E} 6$ & 4105 & 0.35 \\
\hline 70.0 & $9.199 \mathrm{E} 6$ & 4250 & 0.37 & $5.012 \mathrm{E} 6$ & 3956 & 0.34 \\
\hline 75.0 & $7.042 \mathrm{E} 6$ & 4116 & 0.35 & $3.691 \mathrm{E} 6$ & 3812 & 0.33 \\
\hline
\end{tabular}

The graphical illustration in Fig. 1 depicts that the resistance-temperature relationship for the samples is highly non-linear and that the resistance decreases with increasing temperature. It can as well be observed from it that the samples' experimental values of the resistance agree very well with the simulated values obtained using SteinhartHart coefficients. Such phenomenal trend is a clear indication that the samples exhibit temperature coefficient of resistance ( $\alpha$-parameter) that is negative across the relevant temperature range. Fig. 2 shows how the $\alpha$-parameter of the samples trends as a function of temperature. It can be seen on the figure that the relationship illustrated in the plot is nonlinear and that the samples show rapid thermal response, with a higher degree as the CEN proportion increases. 


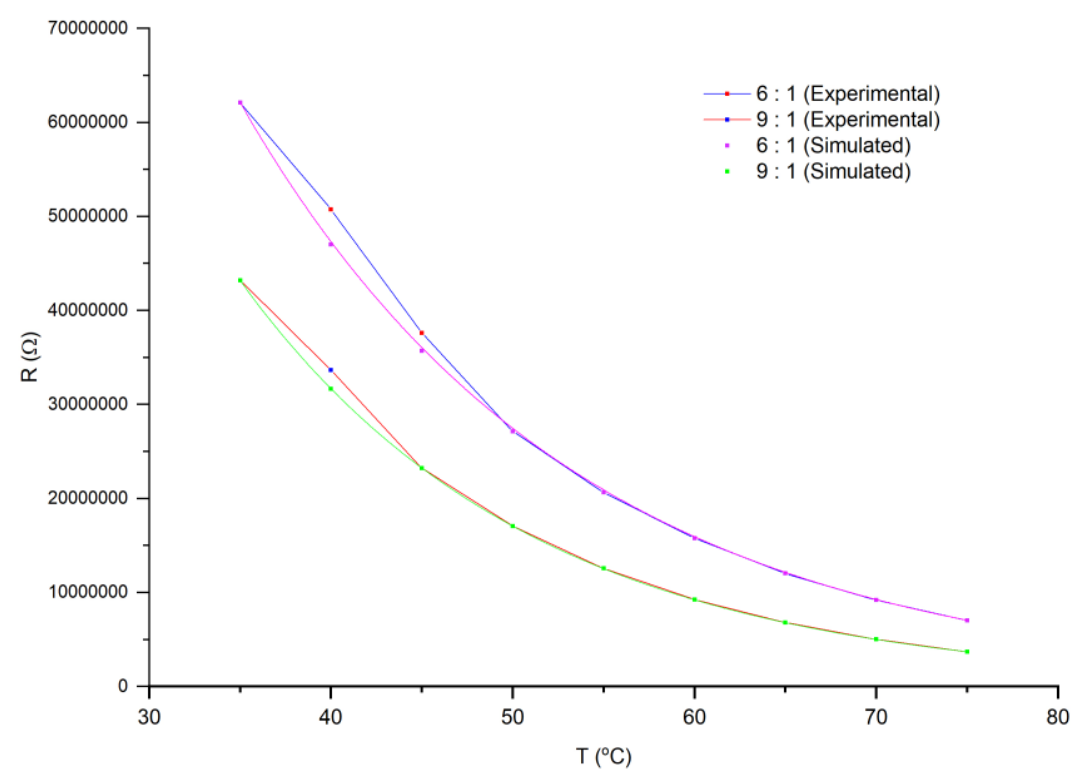

Fig. 1. Variation of the samples' electrical resistance with temperature

Thermal sensitivity index (also known as $\beta$-parameter) is very vital in characterizing samples that have negative $\alpha$ values. The constant $\beta$ - parameter, depending on the basic properties of a material, can be used to provide useful information on the quality of materials to be characterized. In this case, the values of $\beta$-parameter are in inverse relationship with temperature, irrespective of how low or high the CEN proportion is in the samples. The $\beta$ values change from $22.6 \%$ to $25.3 \%$, thereby resulting in a difference of $2.7 \%$ as the proportion of the CEN increases. By assessing these values statistically using one-way analysis of variance, the result (calculated F-value of 1.681 against the critical F-value of 4.494), at 0.05 level of significance, simply reveals that varying the proportion of the CEN in the samples does not significantly affect the obtained values of $\beta$-parameter. This finding means that even though the $\beta$-parameter decreases nonlinearly with increase in temperature (Fig. 3), the samples have a high tendency to remain stable in the event of temperature surges. 


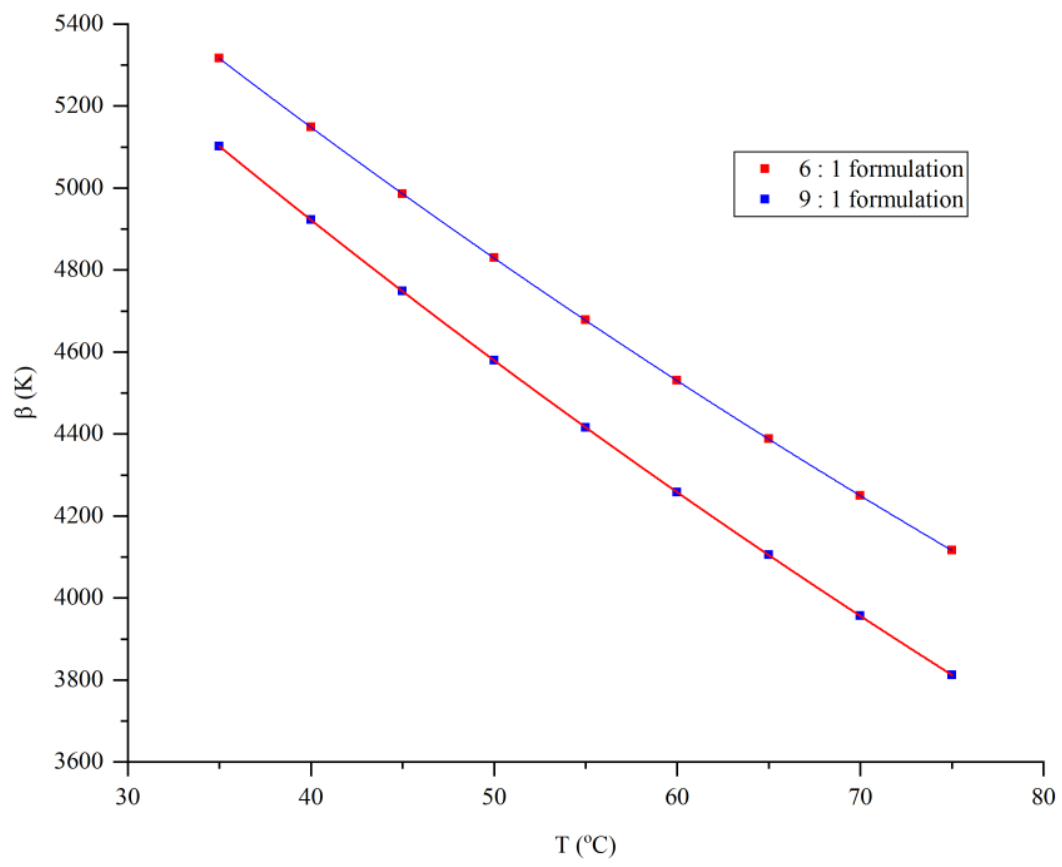

Fig. 2. Variation of the samples' $\alpha$-parameter with temperature

Moreover, the electronic activation energy of the samples is observed to decrease as temperature increases, thereby supporting the observations earlier made in respect of the sensitivity index. Stating in a different way, $\beta$-parameter is associated with the energy required for formation and movement of charge carriers that are responsible for electrical conduction in the samples. Also, electronic activation energy in this context reflects the amount of energy needed for hopping of charge carriers in the samples. Thus, as the value of $\beta$-parameter increases, the insulating (resistive) ability of the samples increases. Now, as lower activation energy is an indication of weak intermolecular forces (which implies ease to trigger a temperature-accelerated failure mechanism), both parameters have a tendency to vary in the same manner with temperature. It can be expressed further that, as the electrical resistance of the samples increases, a greater amount of energy is required to initiate and control conduction over the samples' insulation ability. As such, the activation energy varies in direct trend with the resistance and hence, the $\beta$-parameter.

In general, with the range of values obtained for the samples' characteristics $(\mathrm{R}=$ $3.691 \mathrm{E} 6 \Omega-6.210 \mathrm{E} 7 \Omega, \beta=3812 \mathrm{~K}-5316 \mathrm{~K}$ and $\mathrm{Ea}=0.33 \mathrm{eV}-0.46 \mathrm{eV})$, it is clear that the samples fit the market requirements for NTC thermistor which, as noted by Wiendartun et al [19], are $\mathrm{R} \geq 10 \Omega, \beta \geq 2000 \mathrm{~K}$ and $0.1 \mathrm{eV} \leq \mathrm{Ea} \leq 1.5 \mathrm{eV}$. Also, since the proportion of the CEN is significantly greater than that of the DCS in all the samples used, it is evident enough that the CEN is responsible for the way in which the samples respond to temperature influence. 


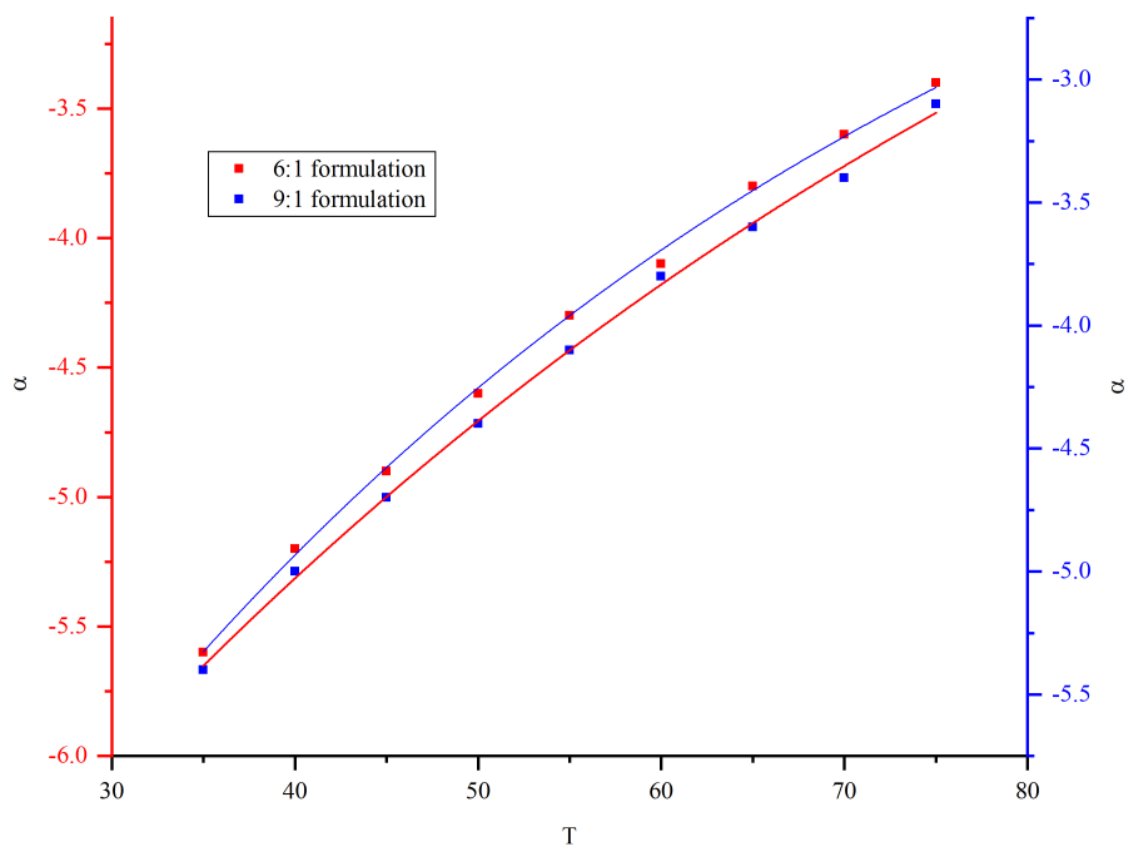

Fig. 3. Variation of the samples' $\beta$-parameter with temperature

\section{CONCLUSIONS}

For the temperature range 35 to $75^{\circ} \mathrm{C}$, the electrical resistance, thermal sensitivity index and electronic activation energy of the samples were found to show substantial nonlinear decrease in their values with increasing temperature. Also, the obtained values were observed to compare favorably with those for NTC thermistors made from other kinds of materials, thereby revealing that the samples fulfill market requirements for engineering applications involving temperature sensing, monitoring or control. Again, it was evident that the calcined eggshell nanopowder component was responsible for the characteristics exhibited by the samples. As such, apart from providing electronic industry with very promising and good alternative materials for fabrication of cost-effective and environmentally friendly components, recycling chicken eggshell wastes and cassava effluents will surely help to reduce environmental pollution caused by such waste materials.

\section{REFERENCES}

[1] Eresor, O.: Comprehensive agricultural science for senior secondary schools, New edn., Glance series, Surulere, Lagos, 2003, p. 187.

[2] Wee, RY.: Top egg producing countries in the world, World facts, 2019, http://worldatlas.com, Accessed 13 March 2019

[3] Martin, H., Frands, D., Robyn, A.: Products and profit from poultry 3, FAO Diversification, Surulere, Lagos, 2012, p. 23.

[4] Olure-Bank, AM.: Int. J. Fin. \& Eco., vol. 3, 2015, p. 107. 
[5] Mwangi, D.: Diversifying livelihood opportunities through poultry farming, http://adesoafrica.org/what-we-do/blogs/diversifying-livelihood-opportunities-throughpoultry-farming/, Accessed 28 April 2015

[6] King’ori, AM.: Res. J. Poul. Sci., vol. 5, 2012, p. 9.

[7] Hunton, P.: Rev. Bras. Cienc. Avic., vol. 7, 2005, p. 67.

[8] Hecht, J.: Eggshells break into collagen market, New Scientist, 1999, https://www.newscientist.com/article/mg16121701-000-eggshells-break-into-collagenmarket/, Accessed 28 October 2019.

[9] Daengprok, W., Garnjanagoonchorn, W., Mine, Y.: Meat Sci., vol. 62, 2002, p. 199.

[10] Wei, Z., Li, B., Xu, C.: Bioresour. Technol., vol. 100, 2009, p. 2883.

[11] Mgbenu, EN., Ifedili, S., Menkiti, AI., Omwuagba, BN.: Waves, Optics and Thermal Physics, Nigerian University Series, Nigeria, 1999, p. 86.

[12] Sedha, RS.: A textbook of applied electronics, Multicolour revised Edn., Ram Nagar, New Delhi, India, 2008, p. 30.

[13] Luo, W., Yao, H., Yang P., Chen, C.: J. Am. Ceramic Society, vol. 92, 2009, p. 2682.

[14] Steinhart, JS., Hart, SR.: Deep-sea Research and Oceanographic Abstracts, vol. 15, 1968, p. 497.

[15] Robert, UW., Etuk, SE., Umoren, GP., Agbasi OE.: Int. J. Thermophys, vol. 40, 2019, p. 83.

[16] ASTM D6393, ASTM International, West Conshokocken, 2014, http://doi.org/10.15.1520/D6393-14

[17] Kanig, JL., Lachman L., Lieberman, HA.: The theory and practice of industrial pharmacy, 3rd edn. (Philadelphia, Germany, 1989)

[18] Carr, RL.: Chem. Eng, vol. 72, 1965, p. 163.

[19] Wiendartun, W., Risdiana, R., Fitrilawati, F., Siregar, RE.: AIP Conference Proceedings, 2015. 